\title{
EDUCAÇÃO, CONDIÇÃO HUMANA E LIBERDADE: UMA ABORDAGEM FREIREANA ${ }^{i}$
}

\author{
CORTE REAL, Márcio Penna*
}

\begin{abstract}
RESUMO
Este artigo problematiza o tema Educação, condição humana e liberdade no pensamento freireano. A exposição privilegia a alegoria da viagem e da imagem de leitura de excertos da obra de Paulo Freire. Levanta-se a hipótese da existência de uma ontologia - visão de ser humano - na obra do autor, necessária para o projeto de mundo, presente na concepção de Educação como prática da liberdade. Ao apresentar a contribuição da dinâmica de investigação dos temas geradores, sustenta que o modo de fazer educação, representado pela Pedagogia do oprimido, configura-se como Ação cultural para a liberdade. Tal ação cultural diz respeito à prática educativa dialógica, problematizadora, amorosa e corajosa o suficiente para levar os seres humanos - educadores (as) e educandas (os) - a refletirem sobre o seu mundo. A educação representa a possibilidade de humanização dos seres humanos, na conceituação de ontologia como ser mais. Argumenta-se, por um lado, que a teorização do humano em Freire apresenta-se como contribuição para organização das práticas educativas em diferentes cenários, da escola aos movimentos sociais. Por outro, respeita à produção do conhecimento educacional em uma perspectiva crítica, no âmbito da ação e da formação de professoras e professores. O empreendimento freireano pretende endereçar os seres humanos ao mundo para, juntos, dialogarem sobre suas situaçõeslimite e sobre a boniteza de o lerem para dizer a sua palavra. O leitmotiv - o fio condutor e a razão de ser - da teorização freireana não é somente a educação, mas o amor radical aos seres humanos, ao mundo e à própria vida.
\end{abstract}

PALAVRAS-CHAVE: Educação; liberdade; humanização; ontologia freireana.

\footnotetext{
* Graduado em Educação Artística - Licenciatura Plena, habilitação em Música; e Mestre em Educação pela UFSM. Doutor em Educação pela UFSC, com estágio de doutorado sanduíche na UFBA com bolsa do CNPq. Professor Associado na Faculdade de Educação da UFG e membro do Programa de Pós-Graduação em Educação/FE/UFG, atuando na linha de pesquisa Cultura e processos educacionais. E-mail: mpcortereal@yahoo.com.br
} 


\title{
EDUCATION, THE HUMAN CONDITION AND FREEDOM: A FREIREAN APPROACH
}

\section{CORTE REAL, Márcio Penna*}

\begin{abstract}
This article places the theme Education, the human conditions and freedom within Freirean thinking. It prioritizes the allegory of the journey and the image of reading excerpts from the work of Paulo Freire. It raises the hypothesis of the existence of ontology - a vision of the human being - in that author's work, necessary for the project of a world presented in the conception of Education, the practice of freedom. In presenting the contribution of the investigative dynamic in the core themes, it holds that the way of carrying out education, represented by Pedagogy of the oppressed, is configured as Cultural action for freedom. This cultural action refers to educational practice that is dialogic, problematizing, loving and courageous enough to lead human beings - the educators and the educated - to reflect on their world. Education represents the possibility of humanizing human beings, in the concept of ontology as being more. On the one hand, it is argued that the theorization of the human in Freire is presented as a contribution to the organization of the educational practices in different situations, from school to social movements. On the other, it respects the production of educational knowledge from a critical perspective, within the scope of the action and formation of teachers. The Freirean undertaking intends to address human beings to the world, so that together they may dialogue about their limit-situations and on the beauty of reading them in order to have their say. The leitmotif - the central thread and raison d'être - of Freirean theorization is not only education, but radical love for human beings, the world and life itself.
\end{abstract}

KEYWORDS: Education; freedom; humanization; Freirean ontology.

\footnotetext{
* Graduated in Arts Education - Full Degree, qualification in Music; and Master of Education from UFSM. PhD in Education at UFSC, with a PhD sandwich at UFBA with a scholarship from CNPq. Associate Professor at the Faculty of Education of UFG and member of the Graduate Program in Education / FE / UFG, acting in the research line Culture and educational processes. E-mail: mpcortereal@yahoo.com.br
} 


\section{INTRODUÇÃO: PROBLEMATIZAÇÃO DO TEMA}

O tema deste artigo, Educação, condição humana e liberdade: uma abordagem freireana, é significativo pelo fato de poder contribuir para a compreensão do projeto políticopedagógico e epistemológico, mas também de mundo e sociedade, representado pela obra de Paulo Reglus Neves Freire ou simplesmente Paulo Freire. Isto é, em textos fundamentais como Educação como prática da liberdade e Pedagogia do oprimido (FREIRE, 1999; 1987) o autor preocupou-se em compreender a posição do ser humano no mundo e com o mundo, mediante os desafios que este se lhes apresenta; e a partir daí traçar as bases da sua teoria do conhecimento, alicerçada por sua pedagogia dialógica.

Neste caminho, procuro esboçar aqui a tese que o tema do humano e, ligado a ele a questão da liberdade, formam o próprio alicerce sobre o qual é construída a prática e a teoria educacional freireana. Isto é, este tema tem um valor no conjunto da obra de Paulo Freire, de tal sorte que é possível afirmar que todo o empreendimento educacional realizado pelo autor visa a contribuir para o processo de humanização dos seres humanos - ou, como ele próprio diria, para que mulheres e homens juntos, como seres humanos em relação e mediatizados pelo mundo, possam projetar e lutar por um mundo mais bonito.

Gostaria de convidar, então, o leitor ou a leitora a acompanhar-me em uma pequena viagem por meio de alguns tópicos fundamentais da obra do autor. Assim, destaco a seguir algumas coordenadas que servem de guias para esta viagem. A primeira coordenada encontrase em Educação como prática da liberdade (FREIRE, 1999), pois, esta é a obra fundante que, se por um lado, serve como base para a apreensão do seu conceito de educação; por outro, é neste texto que emerge a definição daquilo que chamo de ontologia freireana. Ou seja, esta é apreendida na medida em que a condição básica para a apreensão da visão de educação de Paulo Freire requer primar por seu entendimento sobre o papel do humano no mundo, com o mundo e o processo de humanização, no qual a educação ocupa destaque central. Sua ontologia reside não só em uma definição filosófica do ser humano, mas na acepção deste como ser de possibilidades que, no âmbito dos processos educacionais, é desafiado a pensar a sua posição no mundo e com o mundo, sendo esta a condição e a possibilidade para assumir aquilo que Paulo Freire chamou de tomadas de decisões autênticas, decorrentes deste pensamento (FREIRE, 1999).

Na visão de educação que o autor concebeu junto à sua prática de alfabetização de adultos, a partir dos finais dos anos de 1950 e início dos de 1960, no Nordeste Brasileiro e, 
depois a partir do seu exílio, pelo mundo afora, com o advento do golpe militar de 1964, no Brasil, dois conceitos não podem ficar de fora desta pequena viagem, pois formam as outras coordenadas que nos guiam. São eles: o conceito de diálogo e o de amorosidade com qual concluirei esta exposição textual e a nossa pequena viagem.

Portanto, ao tomar como alegoria a ideia de uma viagem, visando a um panorama sintético da teorização de Paulo Freire, pretendo contribuir para a reflexão de aspectos pertinentes tanto à atualidade da sua concepção de Educação como prática da liberdade (FREIRE, 1999); quanto do potencial organizativo para a elaboração de programas de ensino e de pesquisa, em diferentes contextos, os quais podem ser consubstanciados por elementos da dinâmica de investigação de temas geradores no modo de ser e de agir da Pedagogia do oprimido (FREIRE, 1987).

\section{A HUMANIZAÇÃO COMO DESAFIO}

Iniciemos por tentar mapear o entendimento sobre a dimensão e o papel do humano presente na concepção de educação do nosso autor. Este entendimento representa a própria condição humana formulada nos textos freireanos, vez que o homem e a mulher, seres de aprendizagens são, por isso mesmo, seres de possibilidades. Para tanto, convido a leitora ou o leitor a pensar como se estivéssemos abrindo e lendo as páginas iniciais da obra fundadora do seu projeto intelectual, a Educação como prática da liberdade. Esta obra foi publicada, originariamente, em 1967. Este texto traz, em seu bojo, aproximações com a perspectiva teórica de projeto um intelectual anunciado na versão inicial do livro Educação e atualidade brasileira, apresentada por Paulo Freire como tese de livre docência à cadeira de História e Filosofia da Educação, na Escola de Belas-Artes de Pernambuco, em 1959, em que o educador delineia os esboços com os quais iria modelar categorias que perpassaram o conjunto da sua obra (ROMÃO, 2001). Destaca-se, principalmente, a ênfase na história como constituinte de um método de conhecimento capaz de trazer a lume a problematização e a compreensão das grandes questões da educação brasileira, como pretendeu o autor naquela tese e em Educação como prática da liberdade (FREIRE, 2001; 1999). É neste sentido que, numa primeira assertiva, o autor afirma metaforicamente: não ser possível uma compreensão do hoje, sem uma visão do ontem (FREIRE, 1999).

Neste sentido, o convite para a leitura, ao menos de trechos fundamentais, desse livro, significa despertar a atenção para o debate, sempre necessário, sobre algumas características 
históricas e socioculturais, presentes na formação social brasileira. Pois, para Freire, nas condições desta formação social, assentada na base econômica e desumanizante da sociedade escravista e no todo poderosismo dos senhores da terra, encontram-se, também, as raízes do conjunto da problemática da educação - e da própria sociedade brasileira como um todo, que na sua análise tem como marco temporal o final do século XIX e início do XX, advindo daí disposições mentais presentes na vida desta sociedade, materializadas em marcas recorrentes entre nós, como, por exemplo, o assistencialismo, a inexperiência democrática, o mutismo ou silenciamento impingido ao povo e a não participação popular, concernentes àquilo que chamou de educação bancária (FREIRE, 1999). Esta é, assim, uma sociedade reflexa, pois não pensa por si mesma. E o papel da educadora ou do educador dialógico(a)-problematizador(a), neste sentido, é refletir sobre o seu tempo e sobre os desafios presentes no processo histórico dessa sociedade, pois daí, como dito, advém o conjunto da problemática da educação brasileira.

Decorre daí que ao pensar sobre o alcance do ser humano, na leitura inicial do texto freireano - que pode ser considerado porta de entrada para o seu constructo teórico - é mister observar o entendimento que:

As relações que o ser humano trava no mundo com o mundo (...) apresentam uma ordem tal de características que as distinguem totalmente dos puros contatos, típicos da outra esfera animal. Entendemos que, para o ser humano, o mundo é uma realidade objetiva, independente dele, possível de ser conhecida. É fundamental, contudo, partirmos de que o ser humano, não apenas está no mundo, mas com o mundo. (FREIRE, 1999, p. 47).

Isto é, a mulher e o homem, seres históricos que são (somos), transcendem o simples contato com o mundo, na medida em que este nos move, nos instiga e, sendo assim, nos desafia. Isto quer dizer que o mundo, ou seja, o chão concreto da história nos impele a pensar, a agir e a tomar decisões. Aí reside o próprio papel da educação: contribuir para que o educando reflita acerca dos desafios presentes no seu mundo concreto vivido e aja diante deles. Essa primeira leitura sugere compreender, pois o homem e a mulher, como seres de relações, são também seres que têm a cultura, em sentido amplo, e a educação, em sentido particular, como campo de possibilidades para a sua formação e para sua própria humanização, entendida na radicalização da sua vocação ontológica para ser mais. Neste sentido, a sugestão de uma ontologia freireana rompe a mera constatação e definição do estudo do ser e provoca a pensar o próprio processo de assunção do ser humano, no movimento fundante da consciência ingênua rumo à consciência 
crítica, consubstanciada na dinâmica de apreensão e diálogo sobre os temas presentes na realidade existencial (FREIRE, 1987).

Nas palavras do nosso autor, mais uma vez recorrendo às instigantes páginas de Educação como prática da liberdade, Freire (1999, p. 49), vemos que: "Não se reduzindo tãosomente a uma das dimensões de que participa - a natural e a cultural - a primeira, pelo seu aspecto biológico, da segunda, pelo seu poder criador, o homem pode ser eminentemente interferidor."

Ou seja, é esta presença humana no mundo e com o mundo que permite que no seio da práxis, isto é, no processo da ação e reflexão, possamos conceber relações de conhecimento que propiciem que, juntos, façamos coisas como cultura, história, educação, arte, etc.; e sejamos, assim, seres cognoscentes, como diria o autor (Ibid.).

Dito com o autor, vemos que: "Herdando a experiência adquirida, criando e recriando, integrando-se às condições de seu contexto, respondendo a seus desafios, objetivando-se a si próprio, discernindo, transcendendo, lança-se o ser humano num domínio que lhe é exclusivo - o da História e o da Cultura" (FREIRE, 1999, p. 49). Nessa citação residem, a um só tempo, a síntese e o problema a que se dedica a empreitada educacional freireana. Em outras palavras, e mais uma vez de acordo com a Educação como prática da liberdade, será que, em uma sociedade como a brasileira, nascida do colonialismo predador e da formação social escravista violentadora das gentes e das culturas, é possível afirmar que o ser humano fizesse jus à plenitude da sua condição humana?

É necessário ressaltar que tal obra visa à compreensão de um momento em que a sociedade brasileira viveu profundas transformações nos planos político, econômico e cultural. Este contexto histórico de profundas transformações, a partir das décadas de 1920 e 1930, para Freire, não pode ser pensado "sem uma visão do ontem"; pois, no berço da nossa formação social:

Dentro da estrutura econômica do grande domínio, com o trabalho escravo, não teria sido possível um tipo de relações humanas que pudesse criar disposições mentais flexíveis capazes de levar o ser humano a formas de solidariedade que não fossem exclusivamente privadas $(1999$, p. 81).

Em contraposição, é ainda na leitura desta bela obra, a Educação como prática da liberdade, que o problema começa a ser desenvolvido por Freire. Eu incito, mais uma vez, à sua leitura, pois: "Não houvesse esta integração (...), fosse o ser humano apenas um ser de acomodação (...) faltar-lhes-ia a marca da liberdade” (FREIRE, 1999, p. 50). A liberdade é, 
neste sentido, luta, ação e reflexão que contribuam para que sejamos autores das histórias de nossas vidas.

Aí está o problema central, visto que, na leitura desta obra, notamos que: "Uma das tragédias do ser humano moderno está em que é dominado pela força dos mitos e comandado pela publicidade moderna (...) renunciando a sua capacidade de decidir” (FREIRE, 1999, p. 50). E, assim, coisifica-se. Observemos, então, que: "Sua humanização ou desumanização depende em parte da captação dos seus temas (....)” (Ibid.).

Adiante, nesta pequena viagem, a leitura de outra obra fundamental de Paulo Freire é oportuna. Pois, é na abertura das primeiras páginas da Pedagogia do oprimido (FREIRE, 1987) que, mais uma vez, observamos a preocupação com a humanização. Essa obra, assim como Educação como prática da liberdade, é do período de exílio de Paulo Freire, no Chile, e foi escrita em 1968. Acerca do desafio de pensar a posição do ser humano no mundo, Freire convida ao entendido que: a "Humanização e desumanização, dentro da história, num contexto real, concreto, objetivo, são possibilidades dos homens como seres inconclusos e conscientes de sua inconclusão" (FREIRE, 1987, p. 30).

Este problema é ampliado na medida em que: “A desumanização, que não se verifica apenas nos que têm sua humanidade roubada, mas também, ainda que de forma diferente nos que a roubam, é distorção da vocação de ser mais" (FREIRE, 1987, p. 3).

No entanto, a possibilidade da nossa humanização reside em que:

A partir das relações do ser humano com a realidade, resultantes de estar com ela e de estar nela, pelos atos de criação, recriação e decisão, vai ele dinamizando o seu mundo. Vai dominando a realidade. Vai humanizando-a. Vai acrescentado a ela algo que ele mesmo é fazedor. Vai temporalizando os espaços geográficos. Faz cultura. (FREIRE, 1999, p. 51).

E mais, ainda, “(...) na medida em que cria, recria e decide, vão se conformando as épocas históricas. É também criando, recriando, e decidindo que o ser humano deve participar destas épocas" (FREIRE, 1999, p. 51). Esta abordagem sugere não só uma visão de ser humano, que entende sua presença no mundo diante da vocação para ser mais, assumindo que a sua tarefa e desafio primordial tem a ver com a captação e elaboração críticas dos temas do seu tempo, mas uma teoria da cultura ligada aos processos educacionais. Este pressuposto freireano requer a acepção antropológica de cultura (FIORI, 1987), tanto como modo de vida, quanto na sua dimensão dinâmica e transformadora, que desafia aos educadores e às educadoras à 
compreensão de que o seu trabalho lida com a veiculação dos conhecimentos historicamente produzidos pela humanidade e sua ampliação, na forma de produção de novos conhecimentos (FREIRE, 1987; 1999).

Para Freire, desde o berço da nossa história, vivemos em uma sociedade que produziu entre nós um profundo mutismo, na forma de uma cultura do silêncio, a qual é, por essência, antidialogal. Destarte, o problema para o nosso autor pode ser percebido ao questionar: qual é o papel da educação em uma sociedade construída na base do mandonismo, no mando e desmando dos senhores da terra e no silenciamento das populações? Em princípio, o desafio está em romper com a cultura do silêncio e do silenciamento, convidando o ser humano a refletir sobre o seu tempo e sobre seu papel diante dos tempos históricos a serem vividos e tomados como problemas.

Esta linha compreensiva, que apresenta desdobramentos de caráter organizativo e epistemológico para a consecução das práticas educativas, conforme venho chamando atenção, sugere que o papel da educação é devolver ao povo o direito de pensar por si e de dizer a sua palavra. Para dar curso ao entendimento de Educação como prática da liberdade se faz necessário, para o autor, uma abordagem dialógica e colaborativa, na forma de uma Pedagogia do Oprimido. E esta é, de fato, uma Pedagogia do oprimido, porque tem no diálogo o seu fundamento político-pedagógico e no amor ao mundo e aos seres humanos sua opção radical pela vida (FREIRE, 1987).

\section{DiAlogicidade: PROGRAMAÇÃO EDUCATIVA E PRODUÇÃo DO CONHECIMENTO}

Em decorrência do caminho percorrido nesta pequena viagem analítica de excertos da obra freireana, convido o leitor ou a leitora ter presente o entendimento que o diálogo constitui toda a base do projeto educacional de Freire e pretende empoderar os seres humanos por meio do direito de dizerem sua palavra. "Mas, se dizer a palavra verdadeira, que é trabalho, que é práxis, é transformar o mundo, dizer a palavra não é privilégio de alguns homens, mas direito de todos os homens" (FREIRE, 1987, p. 78).

Continuemos na Pedagogia do oprimido para entendermos que: o diálogo é este encontro dos seres humanos, mediatizados pelo mundo, para pronunciá-lo, não se esgotando, portanto na relação eu-tu (FREIRE, 1987, p. 78). O tema do diálogo confunde-se com o do amor ou com a amorosidade. Posto que: "Não há diálogo, porém, se não há um profundo amor 
ao mundo e aos seres humanos. Não é possível a pronúncia do mundo, que é um ato de criação e recriação, se não há amor que a infunda" (FREIRE, 1987, p. 79).

Daí que seja oportuno relembrar o papel desta educação dialógica, como Ação cultural para a liberdade (FREIRE, 1982):

Era ir ao encontro desse povo emerso nos centros urbanos e emergindo já nos rurais e ajudá-lo a inserir-se no processo, criticamente. E esta passagem, absolutamente indispensável à humanização do ser humano brasileiro, não poderia ser feita nem pelo engodo, nem pelo medo, nem pela força. Mas, por uma educação que, por ser educação, haveria de ser corajosa, propondo ao povo a reflexão sobre si mesmo, sobre seu tempo, sobre suas responsabilidades, sobre seu papel no novo clima cultural da época da transição. Uma educação que lhe propiciasse a reflexão sobre próprio poder de refletir e que tivesse sua instrumentalidade, por isso mesmo, no desenvolvimento desse poder, na explicitação de suas potencialidades, de que decorreria sua capacidade de opção. Educação que levasse em consideração os vários graus de poder de captação do ser humano brasileiro da mais alta importância no sentido de sua humanização. (FREIRE, 1999, p. 67).

A educação é, pois, a própria vocação ontológica dos seres humanos. Como prática social, a educação só é possível, na concepção do nosso autor, se tomada como encontro dos seres humanos entre si e com o mundo concreto vivido. Portanto, a partir desta breve trajetória por excertos da obra de Paulo Freire, é inconcebível entendermos a educação (apenas) como ensino, ou como transferência arbitrária de conhecimentos em que o professor que sabe tudo fala e deposita conteúdos nas cabeças de alunos que não sabem nada e devem ficar calados. Tal visão de educação só é possível em visões tradicionais que visam à conservação dos rituais escolares autoritários e da própria sociedade, também autoritária. Por isso, a ideia que esta é uma Pedagogia do oprimido (FREIRE, 1987), ao contrário da pedagogia que se faz de maneira colaborativa e partilhada entre educadores-educandos e educandos-educadores no processo dialógico de investigação dos temas geradores diante do universo existencial das situações desafiadoras vividas nas práticas educativas.

Neste caminho, chamo atenção para o fato da concepção de educação presente nos textos de Paulo Freire acima citados parte, em um primeiro momento, é da pesquisa do universo vocabular dos educandos (FREIRE, 1999) e avança na abordagem dialógica de investigação dos temas geradores, como representações problemáticas das situações concretas vividas por educadores e educandos, diante do mundo da história, da cultura e das relações sociais (FREIRE, 1987). É diante desta concepção que o diálogo se apresenta como busca dos 
conteúdos programáticos para a educação. Isto porque, neste entendimento, "será a partir da situação presente, existencial, refletindo o conjunto das aspirações do povo, que poderemos organizar o conteúdo programático da educação ou da ação política.” (FREIRE, 1987, p. 86)

Esta perspectiva dialógica de investigação dos temas geradores, caro leitor ou leitora, sugere desdobramentos e contribuições para que educadoras e educadores pensem, junto com os seus educandos, a organização das práticas educativas, abrindo margem para avançar na própria produção do conhecimento educacional, como processo de ação reflexão ação. Daí que: "Investigar o tema gerador é investigar o pensar dos homens referido à realidade, é investigar seu atuar sobre a realidade, que é a sua práxis." (Ibid., p. 98).

Sim, trata-se de uma abordagem problematizadora dos contextos educacionais, com potencial tanto para sua organização programática, quanto para a produção do conhecimento, tão caro à atuação e à formação dos professores e das professoras. Isto porque, conforme a abordagem de Henry Giroux (1997) no livro Os professores como intelectuais: rumo a uma pedagogia crítica da aprendizagem, o qual recebeu a apresentação do próprio Paulo Freire (1997), a ênfase atual dos programas de formação inicial e continuada de professores, as condições objetivas de trabalho, a conformação das políticas públicas e uma série de condições adversas têm contribuído para que os professores venham perdendo o seu lugar social e mesmo o seu reconhecimento como trabalhadores intelectuais da educação. Esta é a tese da proletarização do trabalho docente que, entre outros desdobramentos negativos, faz com os que os professores possam ser distanciados da dimensão intelectual do seu trabalho, repercutindo, também, na perda do seu poder profissional, parafraseando Giroux (1997).

Destarte, é significativa a leitura da próxima citação com a qual convido a folhearmos, brevemente, outra obra de igual importância, a Pedagogia da autonomia (FREIRE, 1996, p. 26), quando o nosso professor nos diz:

Ensinar inexiste sem aprender e vice-versa e foi aprendendo socialmente que, historicamente, mulheres e homens descobriram que era possível ensinar. Foi assim socialmente aprendendo, que ao longo dos tempos mulheres e homens perceberam que era possível - depois, preciso - trabalhar maneiras, caminhos, métodos de ensinar. Aprender precedeu ensinar ou, em outras palavras, ensinar se diluía na experiência fundante de aprender.

Essa passagem da teorização filosófico-educacional freireana nos conclama a uma reflexão a partir da qual se conceba o processo educacional como campo de criação de 
possibilidades e condições para aprendizagens recíprocas entre educandos(as)-educadores(as) e educadoras(res)-educandas(os), mediante o mundo que os desafia a produzir encaminhamentos - inclusive, em termos da produção do conhecimento educacional escolar formal - para velhos ou novos problemas. Neste prisma, "A metodologia que defendemos exige que, no fluxo da investigação, se façam ambos sujeitos da mesma - os investigadores e os homens do povo que, aparentemente, seriam seu objeto" (FREIRE, 1987, p. 98).

Se faz mister compreender que esta perspectiva problematiza os papéis tradicionais com os quais são vividas as relações entre educadores(as)-educandos(as) educandos(as)educadores(as) ou mesmo entre pesquisadores(es) e pesquisados(as). O que é contraditório, na medida em que não se trata aqui de pensar na possibilidade de as educadoras e os educadores abrirem mão de seu papel na condução do processo educacional e no percurso de investigação dos temas geradores. Consiste, sim, em um redimensionamento no pensamento e na própria epistemologia educacional, numa perspectiva crítica em que, a partir da contribuição freireana é possível questionar a divisão do trabalho intelectual, característica da educação bancária e das próprias relações sociais que tendem a perpetração de processos excludentes.

Esta perspectiva da contribuição freireana para a epistemologia educacional encontra precedente e foi enfatizada em vários trabalhos (DE BASTOS, 1995; GRABAUSKA, DE BASTOS, 1998; CORTE REAL, 2001; CORTE REAL et al, 2018). Trata-se, pois, de recuperar a contribuição da Pedagogia do oprimido (FREIRE, 1987) para que os educandos-educadores e educadores-educandos, professores e professoras, em particular, possam viver o desafio de assumirem o processo de ação e reflexão junto às práticas educativas na perspectiva da produção de um conhecimento educacional crítico, porque é informado pela realidade problematizada. Neste sentido, a emergência desta ciência social crítica, com ênfase na epistemologia educacional que, conforme autores acima, pode ser vivida em diferentes contextos da escola aos movimentos sociais, mas, especialmente no cenário da formação inicial e continuada de professores e professoras, educadores propriamente ditos, é relevante; ainda mais levada em consideração a velha hierarquia social dos que pensam e os que executam, notadamente a divisão social do trabalho intelectual (MARX, ENGELS, 2001; GIROUX, 1997). Pois, em uma palavra, caso os agentes dos processos educacionais, educadoreseducandos e educandos-educadores, não assumam o desafio de interpretar suas realidades existenciais, estará se postergando o erro do passado ao permitir que as classes dirigentes façam 
as suas leituras de mundo e as transmitam ao conjunto da sociedade como sendo legítimas (GRABAUSKA; DE BASTOS, 1998).

Essa inflexão representa a contribuição da obra de Paulo Freire para a assunção de uma concepção de Educação como prática da liberdade (FREIRE, 1999), que visa a valorizar o lugar do humano como ser de possibilidades, na reivindicação da ontologia freireana em que as mulheres e os homens, seres sociais mediatizados pelo mundo, possam juntos assumir a vocação ontológica de ser mais e de dizer a sua palavra ao viverem, na prática, a Pedagogia do oprimido (FREIRE, 1987). Neste sentido, podem descodificar - isto é, compreender por meio do diálogo entre os sujeitos educacionais e seus contextos, entre a cultura cotidiana e os conhecimentos da cultura escolar - as situações-limite que os tempos presentes vão nos apresentando como desafios. Desafios que, na atualidade, parecem retroagir ao contexto de autoritarismo e de inexperiência democrática, característicos da educação bancária criticada por Freire desde o princípio do seu projeto intelectual; e que encontraram expressão máxima com o golpe militar de 1964, com o qual o autor foi obrigado a deixar o país e a andar pelo mundo como um andarilho da utopia. Essas são algumas balizas para educadores e educadoras assumirem os traçados para novas viagens, isto é, para desenharem seus próprios percursos educacionais.

\section{CONSIDERAÇÕES SOBRE O AMOR AO MUNDO E AOS SERES HUMANOS}

A empreitada teórico-prática de Paulo Reglus Neves Freire visa, prioritariamente, à humanização do ser humano por meio de uma educação corajosa e dialógica, capaz de propor aos sujeitos cognoscentes, educadores(as)-educandos(as) e educandos(as)-educadores(as), pensar sobre os problemas concretos de sua existência. Por isso, a educação, por um lado, funde-se com política, mas por outro, vai além das categorias tradicionais do pensamento ocidental (ANDREOLA, 2000), pois, para Freire (1987), a educação só é possível como ato de amor dos seres humanos entre si e destes para com o mundo.

Assim, podemos lembrar que o próprio autor diz, em depoimento à série de programas radiofônicos da Rádio Nederland, da Holanda, intitulada Paulo Freire: o andarilho da utopia: "Eu sou um intelectual que não tem medo de ser amoroso. Eu amo as gentes e amo o mundo. E é porque amo as pessoas e amo o mundo, que eu brigo para que a justiça social se implante antes da caridade". 
Eis sua opção política ao dizer que: "A posição radical, que é amorosa não pode ser autoflageladora. Não pode acomodar-se passivamente à desumanização de todos, inclusive dos poderosos" (FREIRE, 1999, p. 59). Essa posição teórica complexifica a compreensão das relações opressores e oprimidos, na medida em que a tarefa histórica destes últimos é a de libertarem-se a si mesmos, recusando-se a vir o ocupar o lugar de opressão daqueles.

O tema amorosidade é presente em toda a obra de Paulo Freire. No seu primeiro livro póstumo, Pedagogia da indignação (FREIRE, 2000), livro constituído por cartas enviadas pelo autor a educadores brasileiros, o Professor Balduíno Andreola, amigo e leitor da obra de Freire, em carta prefácio a Paulo Freire, traduz em palavras uma representação do caráter de amorosidade presente no seu pensamento e na sua ação. Convido, então, a adentrarmos na leitura da carta de Balduíno Andreola a Paulo Freire. Diz Andreola:

A leitura atenta de tuas Cartas exigirá de todos nós uma releitura de tua obra. Elas acrescentam novas dimensões, ressignificando, em sua totalidade, o teu legado. Sem esquecer as perspectivas da inteligência, da razão, da corporeidade, da ética e da política, para a existência pessoal e coletiva, enfatizas também o papel das emoções, dos sentimentos, dos desejos, da vontade, da decisão, da resistência, da escolha, da curiosidade, da criatividade, da intuição, da estecidade, da boniteza da vida, do mundo, do conhecimento. No que tange às emoções, reafirmas a amorosidade e afetividade, como fatores básicos da vida humana e da educação (ANDREOLA, 2000, p. 22).

Andreola identifica uma defesa radical da parte de Freire à vida. E o próprio Freire afirma esta defesa quando diz: "Não creio na amorosidade entre mulheres e homens, entre os seres humanos, se não nos tornamos capazes de amar o mundo" (FREIRE apud ANDREOLA, 2000, p. 24). Essa defesa radical à vida, consubstanciada no amor aos seres humanos e no próprio projeto de humanização, assume um tom de denúncia, nas palavras de Andreola (2000, p. 24) dirigidas a Paulo Freire, ainda na carta prefácio da Pedagogia da Indignação:

A civilização ocidental, expressa na racionalidade fria e calculista da filosofia, da ciência e da tecnologia modernas, revelou-se incapaz de salvaguardar os valores que defendes e de articular a linguagem com que te comunicas. Degenerada num projeto de mundo identificado com o desamor da ganância fratricida da posse, do lucro e da especulação financeira, conduziu a humanidade à beira da destruição total. Paulo, há algum tempo venho meditando que me parecias deslocar-te do Ocidente para o Oriente e para o Sul. Lendo tuas Cartas confirmo-me nesta impressão de que, sem renunciar ao vigor da ciência e da filosofia, estás muito mais próximo do pensamento e 
da visão de mundo dos grandes mestres orientais, como também do espírito cósmico, místico acolhedor e musical dos povos africanos.

Termino, pois, este pequeno percurso, sugerindo ao leitor e à leitora as palavras de Paulo Freire, evocada inúmeras vezes pelo estudioso de sua obra, Balduíno Andreola, conclamando, novamente, a pensar no humano. Diz Freire (1987, p. 184) ao final da Pedagogia do Oprimido: "Se nada ficar destas palavras, algo ao menos, esperamos que permaneça: nossa confiança no povo. Nossa fé nos homens e nas mulheres e na criação de um mundo em que seja menos difícil amar".

Esta alusão ao amor como ato revolucionário, a qual Freire toma como inspiração a partir do argentino Ernesto Che Guevara (CHE GUEVARA apud FREIRE, 1987), revela um ponto basilar e cimento da pedagogia freireana. Qual seja, desde a formulação conceitual da concepção de Paulo Freire, presente em textos como Educação e atualidade brasileira (FREIRE, 2002) e Educação como prática da liberdade (FREIRE, 1999), seu projeto políticopedagógico é dinamizado pelo apego ao ser humano e pelo desejo de contribuir para sua assunção e presença crítica no mundo e com o mundo. O papel da educação é, então, o de devolver ao ser humano a sua vocação para ser mais. Esta ambição é, sem dúvida, um ato de amor e mesmo de liberdade, que caracterizou a trajetória e a obra de Paulo Freire.

Cumpre-se destacar, neste ponto de chegada da viagem por alguns pontos relevantes da obra do autor, que sempre é ponto de partida para novas leituras e aprofundamentos das suas proposições teórico-conceituais, que a concepção de Educação como prática da liberdade (FREIRE, 1999) só faz sentido mediante um constructo pedagógico e epistemológico que permita organizar e desenvolver as práticas educativas, como programas de ensino e de pesquisa. Tais programas podem ser articulados pela investigação e apreensão de temas geradores significativos, que desafiem educadoras(es)-educandas(os) e educandas(os)educadoras(es) a juntos dizerem sua palavra como anúncio de um mundo mais humanamente tecido de boniteza, como preconizado pelo dizer da Pedagogia do oprimido (FREIRE, 1987). 


\section{REFERÊNCIAS}

ANDREOLA, Balduíno Antonio. Carta de Paulo Freire às educadoras e aos educadores do Rio Grande do Sul. In.: FREIRE, Paulo. Pedagogia da indignação: cartas pedagógicas e outros escritos. São Paulo: UNESP, 2000, p. 15-25.

CORTE REAL, Márcio Penna. Círculos de cultura na investigação temática de músicas negras: organizando as práticas educativas. 2001. Dissertação (Mestrado em Educação) Programa de Pós-Graduação em Educação, Centro de Educação, Universidade Federal de Santa Maria, Santa Maria, 2001.

ELIAS, Carime Rossi; GOMIDE, Cristina Helou. Dialogicidade e tema gerador: problematização teórico-metodológica para o ensino superior em três momentos pedagógicos. Signos, Fundação Alto Taquari de Ensino Superior. Ano 1 (1975) - Lajeado: Ed. Univates, ano 39, n.1, 2018, p. 179-194.

DE BASTOS, Fábio da Purificação. Investigação-ação educacional emancipatória e prática educacional dialógica em ciências naturais. 1995. Tese (Doutorado em Educação) Faculdade de Educação da Universidade de São Paulo, Instituto de Física da Universidade de São Paulo, Universidade de São Paulo, São Paulo, 1995.

FIORI, Ernani Maria. Aprender a dizer a sua palavra. In.: FREIRE, P. Pedagogia do oprimido. 17 ed. São Paulo: Paz e Terra, p. 5-11.

FREIRE, Paulo. Educação como prática da liberdade. 23 ed. Rio de Janeiro: Paz e Terra, 1999.

Pedagogia do oprimido. 17 ed. São Paulo: Paz e Terra, 1987.

Educação e atualidade brasileira. 2 ed. São Paulo: Cortez, Instituto Paulo Freire, 2002.

Pedagogia da autonomia: saberes necessários à prática educativa. 12 ed. Rio de Janeiro: Paz e Terra, 1996.

. Pedagogia da indignação: cartas pedagógicas e outros escritos. São Paulo: UNESP. 2000.

Ação cultural para a liberdade e outros escritos. 6 ed. Rio de Janeiro: Paz e Terra, 1982.

Apresentação. In.: GIROUX, Henry. Os professores como intelectuais: rumo a uma pedagogia crítica da aprendizagem. Porto Alegre: Artmed, 1997, p. IX-X. 
GRABAUSKA, Claiton José; DE BASTOS, Fábio da Purificação. Investigação-ação educacional: possibilidades críticas e emancipatória na prática educativa. Revista eletrónica HEURESIS de Investigación Curricular e Educativa. Cadiz: v.1, n.2, 1998. Disponível em http://www2.uca.es/HEURESIS/acuerdo. Acessado em: 2000.

GIROUX, Henry. Os professores como intelectuais: rumo a uma pedagogia crítica da aprendizagem. Porto Alegre: Artmed, 1997.

MARX, Karl; ENGELS, Friedrich. Manifesto do partido comunista. Porto Alegre: L\&PM, 2001.

RÁDIO NEDERLAND. Programa radiofônico: Paulo Freire o andarilho da utopia. Holanda, s.d.

ROMÃO, José Eustáquio. Contextualização: Paulo Freire e o Pacto Populista. In.: FREIRE, P. Educação e atualidade brasileira. 2 ed. São Paulo: Cortez, Instituto Paulo Freire, 2002, p. XIII-XLIII.

\section{Nota}

\footnotetext{
${ }^{\mathrm{i}}$ Este artigo foi elaborado a partir de texto base e de anotações, que o autor utilizou para conceber palestra proferida em evento científico da área da educação, tendo permanecido inédito até então. O conjunto das reflexões apresentadas baseiam-se no seu trabalho, como professor, em cursos de formação inicial de professores e na pósgraduação em educação, principalmente, ao ministrar na graduação, de 2009 a 2017, a disciplina de Núcleo Livre, intitulada Paulo Freire: "Educação e atualidade brasileira", na Faculdade de Educação da Universidade Federal de Goiás; na participação de projetos de pesquisa; na publicação, avaliação e edição de trabalhos amparados pela concepção educacional freireana.
} 